\title{
Association of postoperative nausea/ vomiting and pain with breastfeeding success
}

\author{
Ramon Abola* (D), Jamie Romeiser, Suman Grewal, Sabeen Rizwan, Rishimani Adsumelli, Ellen Steinberg \\ and Elliott Bennett-Guerrero
}

\begin{abstract}
Background: Successful breastfeeding is a goal set forth by the World Health Organization to improve neonatal care. Increasingly, patients express the desire to breastfeed, and clinicians should facilitate successful breastfeeding. The primary aim of this study is to determine if postoperative nausea and vomiting (PONV) or postoperative pain are associated with decreased breastfeeding success after cesarean delivery.

Methods: This is a historical cohort study using the Stony Brook Elective Cesarean Delivery Database. Self-reported breastfeeding success at 4 weeks postoperative was analyzed for associations with postoperative antiemetic use and postoperative pain scores. Breastfeeding success was also analyzed for associations with patient factors and anesthetic medications.

Results: Overall, $86 \%$ of patients $(n=81)$ who intended on breastfeeding reported breastfeeding success. Breastfeeding success was not associated with postoperative nausea or vomiting as measured by post anesthesia care unit antiemetic use (15\% use in successful vs. $18 \%$ use in unsuccessful, $p=0.67$ ) or 48 -h antiemetic use (28\% use in successful group vs $36 \%$ use in unsuccessful group, $p=0.732$ ). Pain visual analog scale scores at 6,12 and $24 \mathrm{~h}$ postoperatively were not significantly different between patients with or without breastfeeding success. Breastfeeding success was associated with having had at least 1 previous child ( $86 \%$ vs $36 \%, p<0.001)$. Patients with asthma were less likely to have breastfeeding success ( $45 \%$ vs $4 \%, p=0.002)$.

Conclusions: Efforts to improve PONV and pain after cesarean delivery may not be effective in improving breastfeeding success. To possibly improve breastfeeding rates, resources should be directed toward patients with no previous children and patients with asthma.
\end{abstract}

Keywords: Breastfeeding, Postoperative pain, Postoperative nausea and vomiting (PONV), Prelabor cesarean delivery

\section{Background}

Successful breastfeeding is a goal set forth by the World Health Organization to improve neonatal care (WHO, 2011). The American Academy of Pediatrics (AAP) recommends that children are exclusively breastfed for the first six months of life (So, 2012). Increasingly, patients express the desire to breastfeed, and clinicians should facilitate successful breastfeeding. Previous studies have reported that cesarean deliveries were associated

\footnotetext{
* Correspondence: Ramon.abola@stonybrookmedicine.edu Stony Brook Medicine, Department of Anesthesiology, HSC-4-060, Stony Brook, NY 11794, USA
}

(c) The Author(s). 2017 Open Access This article is distributed under the terms of the Creative Commons Attribution 4.0 International License (http://creativecommons.org/licenses/by/4.0/), which permits unrestricted use, distribution, and reproduction in any medium, provided you give appropriate credit to the original author(s) and the source, provide a link to the Creative Commons license, and indicate if changes were made. The Creative Commons Public Domain Dedication waiver (http://creativecommons.org/publicdomain/zero/1.0/) applies to the data made available in this article, unless otherwise stated.

with a lower breastfeeding rate compared to vaginal deliveries (Prior et al., 2012). This is important because cesarean delivery rates have steadily increased over the past three decades in the United States. Most recently, the Centers for Disease Control reported a cesarean delivery rate of $32.2 \%$ in the United States (Osterman \& Martin, 2014).

After cesarean delivery, routine postoperative care can delay maternal bonding with the infant. A delay in initial breastfeeding has been associated with less successful breastfeeding (Lin et al., 2011; Wallwiener et al., 2016). Our primary objective was to determine if postoperative nausea and vomiting (PONV) after cesarean delivery is 
negatively associated with breastfeeding success. We also evaluated if postoperative pain affects breastfeeding success. We hypothesized that patients who had more PONV and pain would be less successful at breastfeeding.

\section{Methods}

After institutional and ethics approval, a registry was created for patients who presented for prelabor (elective or scheduled) cesarean delivery. Information collected included patient demographics and comorbidities, indications for cesarean delivery, intraoperative management and postoperative outcomes including length of stay, pain scores and use of antiemetics. Patients were contacted by telephone 4 weeks after delivery in order to complete a brief telephone survey. Two questions related to breastfeeding were asked: 1. Did you intend on breastfeeding? 2. Were you successful with breastfeeding? Successful breastfeeding was subjectively defined by each individual patient.

At our institution, patients who present for elective/ scheduled cesarean delivery typically receive a spinal anesthetic with bupivacaine (12 mg), fentanyl (10 mcg) and morphine $(0.2 \mathrm{mg})$. A phenylephrine infusion and a fluid bolus of lactated ringer's are used to decrease the incidence of spinal hypotension. Antiemetics and supplemental intravenous analgesics or sedatives are given as needed. After delivery, patients receive an infusion of oxytocin (20 units over $1 \mathrm{~h}$ and then 5 units/h for $4 \mathrm{~h}$ ). In our post anesthesia care unit (PACU), patients can receive ketorolac $(30 \mathrm{mg}$ ) for postoperative pain. The postoperative analgesia regimen includes intrathecal morphine from the spinal anesthetic, oral acetaminophen, oral ibuprophen and oxycodone as needed.

The data were collected prospectively by anesthesia providers and entered into a Microsoft Access database. This project was authorized by the Stony Brook Medicine Division of Medical and Regulatory Affairs Office as part of the Surgical Quality Improvement Program (SQIP). Following de-identification and extraction of all SQIP patient records, a data analysis was performed as part of the Surgical Quality Data Users Group (SQDUG). The SQIP/SQDUG protocols were approved by our institution's investigational review board (Committees on Research Involving Human Subjects [CORIHS] \#170753-9 - Stony Brook University).

Fisher's exact tests and Wilcox rank sum tests were used to examine association between breastfeeding success and the following variables: comorbidities, ASA classification, intraoperative sedative and analgesic medications, PACU antiemetics, $48 \mathrm{~h}$ antiemetics, parity, and Visual analog scale (VAS) score at 6,12 and $24 \mathrm{~h}$ after surgery. All calculations were performed at an alpha of 0.05 using SAS 9.4 Software (C) (SAS Institute Inc., Cary, NC).

\section{Results}

Information was collected for 391 patients who presented to Stony Brook University Medical Center between October 2013 and September 2014 for elective or scheduled cesarean delivery. Overall, 132 patients completed a post-discharge telephone survey 4 weeks after surgery (34\% survey completion). Ninety-four surveyed patients $(71 \%)$ stated that they intended to breastfeed. Further analysis was performed on this cohort who intended to breastfeed. Eighty one patients $(86 \%)$ reported successful breastfeeding and 11 patients (11\%) reported they were unsuccessful with breastfeeding; two did not report on their success (2\%).

With regard to our primary objective, breastfeeding success was not associated with PONV. Breastfeeding success was not associated with PACU antiemetic use (15\% use in successful vs. $18 \%$ use in unsuccessful, $p=0.67)$. Breastfeeding success was not found to be associated with 48 -h antiemetic use (28\% use in successful vs. $36 \%$ use in unsuccessful, $p=0.73$, Table 1 ). Pain visual analog scale scores (VAS) at 6, 12 and $24 \mathrm{~h}$ postop were not significantly different between patients with or without breastfeeding success (Table 2).

Breastfeeding success was positively associated with having previous children: $86 \%$ of those who reported success had at least one previous child; just $36 \%$ of those who were unsuccessful had at least one previous child $(p<0.001)$. Patient comorbidities had a negative affect: $91 \%$ of those who were not successful had some type of co-morbidity. This proportion was significantly lower (51\%) in those who reported success $(p=0.02)$. Specifically, a higher proportion of those who reported unsuccessful breastfeeding were asthmatic (46\% vs. $6 \%, p=0.002)$. Diabetes also trended toward significance in this direction. Breastfeeding success was not found to be associated with ASA score, or need for intraoperative sedative or analgesic medication $(p=1)$. However, there was a difference in anesthetic technique; a higher proportion of those who reported unsuccessful breast feeding had a combined spinal/epidural compared to those who reported successful breast feeding (27\% vs. $1 \%$, $p=0.005$ ).

Surveyed patients were compared to non-surveyed patients $(n=259)$ for differences in demographics, pre and post -operative information. Aside from having a lower ASA score in the surveyed group, there were no discernible differences (not shown).

\section{Discussion}

Our analysis found no association between breastfeeding success and PONV or postoperative pain scores. We hypothesized that a better recovery profile would 
Table 1 Breastfeeding success and antiemetic use, demographics, comorbidities, and delivery characteristics

\begin{tabular}{|c|c|c|c|}
\hline Patient Characteristics & $\begin{array}{l}\text { Unsuccessful } \\
\text { Breastfeeding }\end{array}$ & $\begin{array}{l}\text { Successful } \\
\text { Breastfeeding }\end{array}$ & $p$ value \\
\hline $\begin{array}{l}\text { Total Number of } \\
\text { Patients }\end{array}$ & $n=11$ & $n=81$ & \\
\hline \multicolumn{4}{|l|}{ Antiemetic Use } \\
\hline PACU Antiemetics & $2(18.2 \%)$ & $12(14.8 \%)$ & 0.67 \\
\hline 48 Hour Antiemetics & $4(36.4 \%)$ & $23(28.4 \%)$ & 0.73 \\
\hline \multicolumn{4}{|l|}{ Demographics } \\
\hline $\begin{array}{l}\text { Age (Years) - Median } \\
\text { (IQR) }\end{array}$ & $33(28-34)$ & $33(28-36)$ & 0.66 \\
\hline $\begin{array}{l}\text { Height (cm) - Median } \\
\text { (IQR) }\end{array}$ & $160(157-165)$ & $162(157-167)$ & 0.44 \\
\hline $\begin{array}{l}\text { Weight (kg) - Median } \\
\text { (IQR) }\end{array}$ & $93(70-100)$ & $84.5(74-94.5)$ & 0.68 \\
\hline $\begin{array}{l}\text { BMI }\left(\mathrm{kg} / \mathrm{m}^{2}\right) \text { - Median } \\
\text { (IQR) }\end{array}$ & $35.4(27.1,39.6)$ & $32(28.3-36)$ & 0.53 \\
\hline $\begin{array}{l}\text { Ethnicity (Caucasian } \\
\text { vs. Non) }\end{array}$ & $7(63.6 \%)$ & $53(65.4 \%)$ & 1 \\
\hline Parity $(\geq 1)$ & $4(36.4 \%)$ & $70(86.4 \%)$ & $<0.001$ \\
\hline \multicolumn{4}{|l|}{ ASA Classification } \\
\hline - ASA I & $2(18.2 \%)$ & $32(39.5 \%)$ & 0.32 \\
\hline - ASA \| & $8(72.7 \%)$ & $45(55.6 \%)$ & \\
\hline - ASA III & $1(9.1 \%)$ & $4(4.9 \%)$ & \\
\hline $\begin{array}{l}\text { Gestational Age } \\
\text { (Weeks) - } \\
\text { Median (IQR) }\end{array}$ & $39(38-39)$ & $39(39-39.2)$ & 0.07 \\
\hline \multicolumn{4}{|l|}{ Comorbidities } \\
\hline Any Co-Morbidity & $10(90.9 \%)$ & $41(50.6 \%)$ & 0.02 \\
\hline History of PONV & $0(0 \%)$ & $13(16.5 \%)$ & 0.35 \\
\hline Diabetes & $3(27.3 \%)$ & $6(7.4 \%)$ & 0.07 \\
\hline Asthma & $5(45.5 \%)$ & $5(6.2 \%)$ & 0.002 \\
\hline Other Condition & $4(36.4 \%)$ & $31(38.3 \%)$ & 1 \\
\hline \multicolumn{4}{|l|}{ Delivery Characteristics } \\
\hline \multicolumn{4}{|c|}{ Indications for cesarean delivery } \\
\hline Repeat Cesarean & $4(36.4 \%)$ & $60(75.0 \%)$ & 0.01 \\
\hline Malpresentation & $1(9.1 \%)$ & $10(12.7 \%)$ & 1 \\
\hline Macrosomia & $2(18.2 \%)$ & $2(2.5 \%)$ & 0.07 \\
\hline Multiple gestation & $1(9.1 \%)$ & $4(5.0 \%)$ & 0.48 \\
\hline \multicolumn{4}{|l|}{ Anesthetic technique } \\
\hline - Spinal & $8(72.7 \%)$ & 80 (98.8\%) & 0.005 \\
\hline $\begin{array}{l}\text { - Combined Spinal } \\
\text { Epidural }\end{array}$ & $3(27.3 \%)$ & $1(1.2 \%)$ & \\
\hline $\begin{array}{l}\text { Any Intraoperative } \\
\text { Sedatives or Analgesics }\end{array}$ & $2(18.2 \%)$ & 19 (23.5\%) & 1 \\
\hline $\begin{array}{l}\text { Any Intraoperative } \\
\text { Antiemetics }\end{array}$ & $6(54.6 \%)$ & 50 (63.3\%) & 0.74 \\
\hline
\end{tabular}

facilitate success at breastfeeding and that PONV and pain might make women more likely to give up trying to breastfeed. A previously published survey study demonstrated that mothers with increased pain after cesarean delivery had increased problems with breastfeeding (Karlstrom et al., 2007). We could find no data in the
Table 2 Breastfeeding success and visual analog scale (VAS) pain scores

\begin{tabular}{lllc}
\hline & $\begin{array}{l}\text { Unsuccessful } \\
\text { Breastfeeding }\end{array}$ & $\begin{array}{l}\text { Successful } \\
\text { Breastfeeding }\end{array}$ & $\begin{array}{c}\text { P-value, Wilcox } \\
\text { rank sum test }\end{array}$ \\
\hline VAS 6 Hours & $n=10$ & $n=73$ & \\
$\quad$ Median (Q1/Q3) & $1.5(0 / 4)$ & $3(0 / 4)$ & 0.56 \\
$\begin{array}{l}\text { Mean (Upper/Lower } \\
\text { 95\%) }\end{array}$ & $2.0(0.7-3.4)$ & $2.73(2.1-3.3)$ & \\
VAS 12 Hours & $n=9$ & $n=75$ & \\
Median (Q1/Q3) & $1(0 / 1)$ & $2(0 / 5)$ & 0.39 \\
$\begin{array}{l}\text { Mean (Upper/Lower } \\
\text { 95\%) }\end{array}$ & $1.6(0-3.3)$ & $2.6(1.9-3.2)$ & \\
VAS 24 h & $n=10$ & $n=80$ & \\
$\begin{array}{l}\text { Mean (Upper/Lower } \\
\text { 95\%) }\end{array}$ & $4.5(2 / 6)$ & $3(1 / 5)$ & 0.31 \\
Median (Q1/Q3) & $4.1(2.2-6.1)$ & $3.2(2.6-3.8)$ & \\
\hline
\end{tabular}

medical literature that correlated breastfeeding success with maternal PONV.

Our study found that mothers with previous children were more likely to be successful at breastfeeding, which is consistent with prior studies (Sutherland et al., 2012). It is interesting to note that mothers with asthma were much more likely to be unsuccessful at breastfeeding. It is unclear from our study if asthma causes a physical limitation that affects breastfeeding, or if asthma is a surrogate for demographic differences such as tobacco abuse or lower socioeconomic status. Lower socioeconomic status has been associated with lower breastfeeding rates (Brand et al., 2011). Future research should evaluate if improving breastfeeding rates in asthmatic mothers results in improved long-term outcomes for their children. A meta-analysis found that breastfeeding was associated with decreased incidence of asthma in children (Dogaru et al., 2014). Targeting breastfeeding resources toward first time mothers and asthmatic mothers may increase rates of breastfeeding success.

There are a limited number of studies that have looked at the effects of neuraxial anesthesia during childbirth on breastfeeding. Previous studies have suggested that epidural analgesia in labor is associated with lower breastfeeding rates (Baumgarner et al., 2003; Torvaldsen et al., 2006). However, a study by Halpern drew opposite conclusions demonstrating high breastfeeding rates in both patients who received or did receive labor epidural analgesia (Halpern et al., 1999). A systematic review found inconclusive evidence within the medical literature to determine the effect of epidural analgesia on breastfeeding (French et al., 2016).

A systematic review of breastfeeding worldwide reported a lower rate of breastfeeding in patients who had a cesarean versus a vaginal delivery (pooled odds ratio: $0.57195 \% \mathrm{CI} 0.50,0.64, \mathrm{P}, 0.00001)$. The rates of 
breastfeeding were also lower in patients who had a prelabor (elective/scheduled) cesarean delivery versus an emergency, in-labor cesarean delivery (prelabor odds ratio: $0.83,95 \%$ CI $0.80,0.86, \mathrm{P}, 0.00001$, in labor odds ratio: 1.00, 95\% CI 0.97, 1.04; $P=0.86$ ) (Prior et al., 2012). The authors of this review speculated on several possible reasons for these findings. The first hours after delivery are important to establish breastfeeding between a mother and neonate. Postoperative evaluations and interventions may impede the creation of this bond between mother and child. Another idea is that there may be hormones released in labor that promote breastfeeding that are not released in prelabor cesarean delivery patients. However, these authors also observed that there were no differences at 6 months between vaginal delivery and cesarean delivery in the patients who had successful early breastfeeding (Thompson et al., 2010). Patients with greater blood loss due to postpartum hemorrhage were less likely to initiate and sustain full breastfeeding. There is speculation that less successful breastfeeding in these patients may be related to delays in initial contact/bonding between mother and child.

The World Health Organization reports that the exclusive breastfeeding rate at 6 months of life for newborns worldwide is $40 \%$. (Global breastfeeding scorecard, 2017) In the United States, two thirds of mothers breastfed in the 1900s. Breastfeeding rates declined over the twentieth century reaching a nadir in 1972 with breastfeeding rates of $22 \%$. Factors that are associated with the declining rates of breastfeeding include the increased use of breast milk substitutes, the need to return to work away from their babies, and lack of family support (Global breastfeeding scorecard, 2017; Raffle et al., 2011; Wolf, 2003). Breastfeeding rates have increased over the last few decades (Wolf, 2003).

Our high level of breastfeeding success may have little to do with the anesthetic management and may be more reflective of institutional policies that encourage breastfeeding. Our institution has worked toward earning a "Baby-Friendly" designation by instituting the AAP's Ten Steps to Successful Breastfeeding (So, 2012). Examples of these practices at our hospital include breastfeeding in the PACU after cesarean delivery, mothers and infants "room in" remaining together $24 \mathrm{~h}$ a day, pacifiers are not provided to the infants, postpartum lactation consultant services are available, and breastfeeding training is completed by all nursing staff. $32 \%$ of mothers at our institution exclusively breastfed during their hospital admission in 2012. Three years later, the exclusive breastfeeding rate increased to 56\% of mothers in 2015 . Implementation of these breastfeeding policies has allowed for consistently high rates of breastfeeding over time at other institutions (Philipp et al., 2003).
There are several limitations of this study. This is a historical cohort study and is thus subject to bias. Our breastfeeding analysis was performed in only 94 patients with completed survey data. Inclusion of more patients may have influenced our findings. Inclusion of more patients may have influenced our findings. We performed a sample size calculation that asked how many patients we would have needed in our study to obtain statistical significance with regard to breastfeeding, antiemetic use and pain scores. We calculated that we would have needed 3000 patients to detect a statistically significant difference in antiemetic use and breastfeeding success, and approximately 500-800 patients to detect a significant difference in pain score and breastfeeding success. We cannot rule out there being some association, however, these large required sample sizes suggest that any effect is probably small, given the large number of patients likely needed.

We used antiemetics as a well-established surrogate measure of PONV, however, it is possible that some patients may have had nausea but did not receive antiemetics (Myles \& Wengritzky, 2012). Our definition of breastfeeding was subjective for each individual patient. We chose a subjective definition of breastfeeding success, as there is variability to what constitutes success between patients. Breastfeeding success could be defined as 1 . successful breastfeed with formula supplementation (complementary feeding), 2. breastfeeding for 6 weeks until return to work, or 3 . exclusive breastfeeding for 6 months. More objective measures (breastfeeding initiation, exclusive breastfeeding, breastfeeding at 6 months) may have provided more clinically meaningful information. Further investigation into the reasons as to why $29 \%$ of our patients did not intend to breastfeed may provide better insight into how to improve exclusive breastfeeding rates.

\section{Conclusions}

Breastfeeding success was not found to be associated with postoperative nausea and vomiting or postoperative pain. Efforts to improve PONV and pain after cesarean delivery may not be effective in increasing rates of breastfeeding success. To possibly improve breastfeeding rates, resources should be directed toward patients with no previous children and patients with asthma.

\footnotetext{
Abbreviations

AAP: American Academy of Pediatrics; PACU: Post anesthesia care unit; PONV: Postoperative nausea and vomiting; SQDUG: Surgical quality data use group; SQIP: Surgical quality improvement program; VAS: Visual Analog Scale

Acknowledgements

Not applicable

Funding

Funding for this project was provided by the Stony Brook Department of Anesthesiology.
} 


\section{Availability of data and materials}

The datasets generated and/or analyzed during the current study are not publicly available due to the fact that they contain personal health information but are available from the corresponding author on reasonable request.

\section{Authors' contributions}

RA (corresponding) was project coordinator, analyzed and interpreted the patient data and was in charge of the manuscript. JR was our statistician and created our database. SG, SR were the administrators of the database. RA, ES were involved in development of this project. EBG was involved in analysis and interpretation of patient data and manuscript preparation. All authors read and approved the final manuscript.

\section{Ethics approval and consent to participate}

Our study was approved by the Stony Brook University Institution Review Board. Reference \#170753-9.

\section{Consent for publication}

Not Applicable

\section{Competing interests}

The authors declare that they have no competing interests.

\section{Publisher's Note}

Springer Nature remains neutral with regard to jurisdictional claims in published maps and institutional affiliations.

Received: 12 January 2017 Accepted: 27 October 2017

Published online: 22 November 2017

\section{References}

Baumgarner DJ, Muehl P, Fischer M, Pribbenow B. Effect of labor epidural anesthesia on breast feeding of healthy full term newborns delivered vaginally. J Am Board Fam Pract. 2003;16:7-13.

Brand E, Kothari C, Stark MA. Factors related to breastfeeding discontinuation between hospital discharge and 2 weeks postpartum. J Perinat Educ. 2011; 20(1):36-44.

Dogaru CM, Nyffenegger D, Pescatore AM, Spycher BD, Kuehni CE. Breastfeeding and childhood asthma: systematic review and meta-analysis. Am J Epidemiol. 2014;179(10):1153-67.

French CA, Cong X, Chung KS. Labor epidural analgesia and breastfeeding: a systematic review. J Hum Lact. 2016;32(3):507-20.

Halpern SH, Levine T, Wilson DB, MacDonnell J, Katsiris SE, Leighton BL. Effect of labor analgesia of breastfeeding success. Birth. 1999;26(2):83-8.

Karlstrom A, Engstrom-Olofsson R, Norbergh KG, Sjoling M, Hildingsson I. Postoperative pain after cesarean birth affects breastfeeding and infant care. J Obstet Gynecol Neonatal Nurs. 2007:36(5):430-40.

Lin SY, Lee JT, Yang CC, Gau ML. Factors related to milk supply perception in women who underwent cesarean section. J Nurs Res. 2011;19(2):94-101.

Myles PS, Wengritzky R. Simplified postoperative nausea and vomiting impact scale for audit and post-discharge review. Br J Anaesth. 2012;108(3):423-9.

Osterman MJ, Martin JA. Trends in low-risk cesarean delivery in the United States, 1990-2013. National Vital Statistics Reports. 2014;63(6):1-16.

Philipp BL, Malone KL, Cimo S, Merewood A. Sustained breastfeeding rates at a US baby-friendly hospital. Pediatrics. 2003;112:e234-6.

Prior E, Santhakumaran S, Gale C, Philipps LH, Modi N, Hyde MJ. Breastfeeding after cesarean delivery: a systematic review and meta-analysis of world literature. Am J Clin Nutr. 2012;95(5):1113-35.

Raffle $H$, Ware $L$, Borchardt A, STrickland H. Factors that influence breastfeeding initiation and persistence in Ohio's Appalachian region. Athens: Boinovich School of Leadership and Public Affairs at Ohio University; 2011.

So B. Breastfeeding and the use of human milk. Pediatrics. 2012;129(3):e827-41.

Sutherland T, Pierce CB, Blomquist JL, Handa VL. Breastfeeding practices among first-time mothers and across multiple pregnancies. Matern Child Health J. 2012;16(8):1665-71.

Thompson JF, Heal LJ, Roberts CL, Ellwood DA. Women's breastfeeding experiences following a significant primary postpartum haemorrhage: a multicentre cohort study. Int Breastfeed J. 2010;5:5.
Torvaldsen S, Roberts CL, Simpson JM, Thompson JF, Ellwood DA. Intrapartum epidural analgesia and breastfeeding: a prospective cohort study. Int Breastfeed J. 2006; 1:24.

Wallwiener S, Muller M, Doster A, Plewniok K, Wallwiener CW, Fluhr H, et al: Predictors of impaired breastfeeding initiation and maintenance in a diverse sample: what is important? Arch Gynecol Obstet. 2016;294(3):455-66.

WHO. Exclusive breastfeeding for six months best for babies everywhere. 2011 [Available from: http://www.who.int/mediacentre/news/statements/2011/ breastfeeding_20110115/en/. Accessed 1 Oct 2017.

WHO. Global breastfeeding scorecard, 2017. Switzerland: Tracking Progress for Breastfeeding Policies and Programmes Geneve; 2017. [Available from: http://www.who.int/nutrition/publications/infantfeeding/global-bfscorecard-2017.pdf?ua=1. Accessed 1 Oct 2017.

Wolf JH. Low breastfeeding rates and public health in the United States. Am J of Public Health. 2003;93(12):2000-10.

\section{Submit your next manuscript to BioMed Central and we will help you at every step:}

- We accept pre-submission inquiries

- Our selector tool helps you to find the most relevant journal

- We provide round the clock customer support

- Convenient online submission

- Thorough peer review

- Inclusion in PubMed and all major indexing services

- Maximum visibility for your research

Submit your manuscript at www.biomedcentral.com/submit
Biomed Central 